\title{
UMA IZIDORA E DUAS ROSAS: NOTAS PARA \\ UMA PERSPECTIVA DO ESPAÇO PROTAGONIZADA POR MULHERES NEGRAS
}

\author{
Natália Alves da Silva* \\ *Universidade Federal do Rio de Janeiro, Instituto de Pesquisa e Planejamento Urbano e Regional, Rio de \\ Janeiro, RJ, Brasil
}

\begin{abstract}
Resumo
O presente artigo tem como objetivo discutir o protagonismo das mulheres negras nas disputas de lugar ocorridas, em três tempos históricos distintos, na região da Izidora, onde atualmente se localizam as ocupações Vitória, Esperança e Rosa Leão, situada no vetor norte da cidade de Belo Horizonte, capital de Minas Gerais. O que se busca mostrar é a convergência entre as lutas em torno da permanência das comunidades na dimensão físico-territorial e das lutas por nomeação do lugar. As perspectivas feministas negras são tomadas, enquanto epistemologia, para construir um quadro conceitual que, ao problematizar análises unidimensionais da produção do espaço, dá visibilidade às múltiplas dinâmicas que se entrecruzam no espaço e no tempo, informadas por gênero, raça e classe.

Palavras-chave

Protagonismo das Mulheres Negras; Izidora; Disputas de Lugar; Feminismo Negro; Narrativas.
\end{abstract}




\title{
ONE IZIDORA AND TWO ROSAS: NOTES FOR A PERSPECTIVE ON A SPACE PROTAGONIZED BY BLACK WOMEN
}

\author{
Natália Alves da Silva* \\ *Universidade Federal do Rio de Janeiro, Instituto de Pesquisa e Planejamento Urbano e Regional, Rio de \\ Janeiro, RJ, Brazil
}

\begin{abstract}
The aim of this article is to discuss the leading role played by Black women in disputes over place, which have occurred at three different historical moments, in the region of Izidora, where the Vitória, Esperança and Rosa Leão occupations are currently located, in the north zone of Belo Horizonte, state capital of Minas Gerais. The article seeks to demonstrate a convergence between the struggles of the communities to remain in the physical-territorial dimension and their struggles to name it. Black feminist perspectives are taken as epistemology, in order to build a conceptual framework that, by problematizing unidimensional analyzes of the production of space, provides visibility to the multiple dynamics that intersect in space and time, informed by gender, race and class.

Keywords

Protagonism of Black Women; Izidora; Disputes over Place; Black Feminism; Narratives.
\end{abstract}




\section{UMA IZIDORA E DUAS ROSAS: NOTAS PARA UMA PERSPECTIVA DO ESPAÇO PROTAGONIZADA POR MULHERES NEGRAS}

Natália Alves da Silva

\section{Introdução}

O nome chamou minha atenção. Das três ocupações urbanas que formam a região da Izidora (Vitória, Esperança e Rosa Leão), este último parecia ser o que mais explicitamente fazia referência a uma existência concreta. Os nomes Vitória e Esperança representavam, por certo, o desejo coletivo de conquista das moradias. Já Rosa Leão escapava a qualquer conclusão definitiva. Poderia, por exemplo, ter resultado da junção de dois elementos escolhidos para representar uma coletividade em que a participação feminina se mostrava, além de ativa, bastante aguerrida. A flor representaria, talvez, uma suposta delicadeza, e o leão, uma força presumida. Contava, em favor dessa hipótese, o fato de, logo nos primeiros dias da deflagração do conflito fundiário, em 2013, durante uma ação de solidariedade, artistas da região terem pintado, no barracão destinado às atividades comunitárias e de coordenação, um leão que segurava uma rosa. Intrigava-me, no entanto, o uso do vocábulo "Leão" para dar nome a uma ocupação que deve sua existência sobretudo à ação comunitária desenvolvida majoritariamente por mulheres. Ou seria um sobrenome? A questão do nome permaneceria em aberto, ao longo dos três anos seguintes, até o início do meu trabalho acadêmico junto à comunidade.

Foi apenas em 2016, já no desenvolvimento do meu trabalho de pesquisa, que se ocupava em instaurar uma perspectiva feminista negra baseada no paradigma da interseccionalidade para as disputas espaciais protagonizadas por mulheres negras na Izidora (SILVA, 2018), que pude saber mais sobre a vida e a trajetória de Rosa de Jesus Leão. $O$ ato de nomeação da ocupação pelas/os ocupantes tornou-se 
especial para mim e alterou os rumos da minha investigação, pois me instigou a propor novos ângulos de leitura acerca das disputas de lugar travadas no transcurso dos cinco anos de ameaças de despejo das ocupações, conectando-as à larga temporalidade dos embates realizados na região em torno da construção e da permanência de seus territórios, protagonizados por mulheres, historicamente apagadas dos registros oficiais e das pesquisas acadêmicas. Para isso, reuni informações sobre Izidora da Costa, que viveu no século XIX e dá nome à região em disputa, e sobre Rosa de Jesus Leão (1954-2002). As conversas com Charlene Egídio (1981-), moradora e coordenadora da Ocupação Rosa Leão, adensaram o debate sobre a historicidade das ocupações.

O presente artigo objetiva apresentar uma proposta de leitura do conflito baseada numa visada interseccional, contributo das perspectivas feministas negras. Na primeira seção, traço uma cartografia do conflito da Izidora, relacionando-o a territórios da região em que as mulheres negras foram protagonistas. Busco evidenciar a indissociabilidade entre as lutas pela permanência no território e a luta por sua nomeação. Na seção seguinte, discuto em que medida as leituras do espaço fornecidas pelos estudos urbanos tendem a invisibilizar o protagonismo das mulheres negras e suas práticas espaciais. Apresento também o percurso metodológico que me permitiu tecer o fio narrativo que conecta três mulheres negras em tempos distintos, o que possibilita a reconstrução da cartografia do conflito e amplia o escopo das lutas por território figurado pelos atos de nomeação. Discuto por fim, com base em fragmentos das narrativas de Izidora, Rosa e Charlene, o protagonismo das mulheres negras e suas formulações sobre as práticas espaciais na formação do território.

\section{Disputas de território e territórios em disputa}

Rosa Leão, Esperança e Vitória formam as ocupações da Izidora (Figura 1), em Belo Horizonte, onde vivem cerca de dez mil famílias que, desde 2013, enfrentam a ameaça judicial de despejo. Última grande reserva de área verde de Belo Horizonte, a "mata do Isidoro", como a região é identificada nos registros oficiais, está localizada no bairro Granja Werneck, vetor norte do município, por onde se expande a fronteira metropolitana (Figura 2), mobilizada por altos investimentos em obras, como a da Linha Verde, que dá acesso ao Aeroporto Internacional de Confins, e a da Cidade Administrativa do Estado de Minas Gerais (COSTA; MAGALHÃES, 2011). Numa comprovação da dimensão trans-histórica dessa disputa pelo território na capital mineira, o conflito foi selecionado, em 2016, como um dos sete casos mais emblemáticos do mundo para ser apresentado no Tribunal Internacional de Despejos, em Quito, Equador, durante a III ONU-Habitat (FRANZONI; ALVES; FARIA, 2018). 


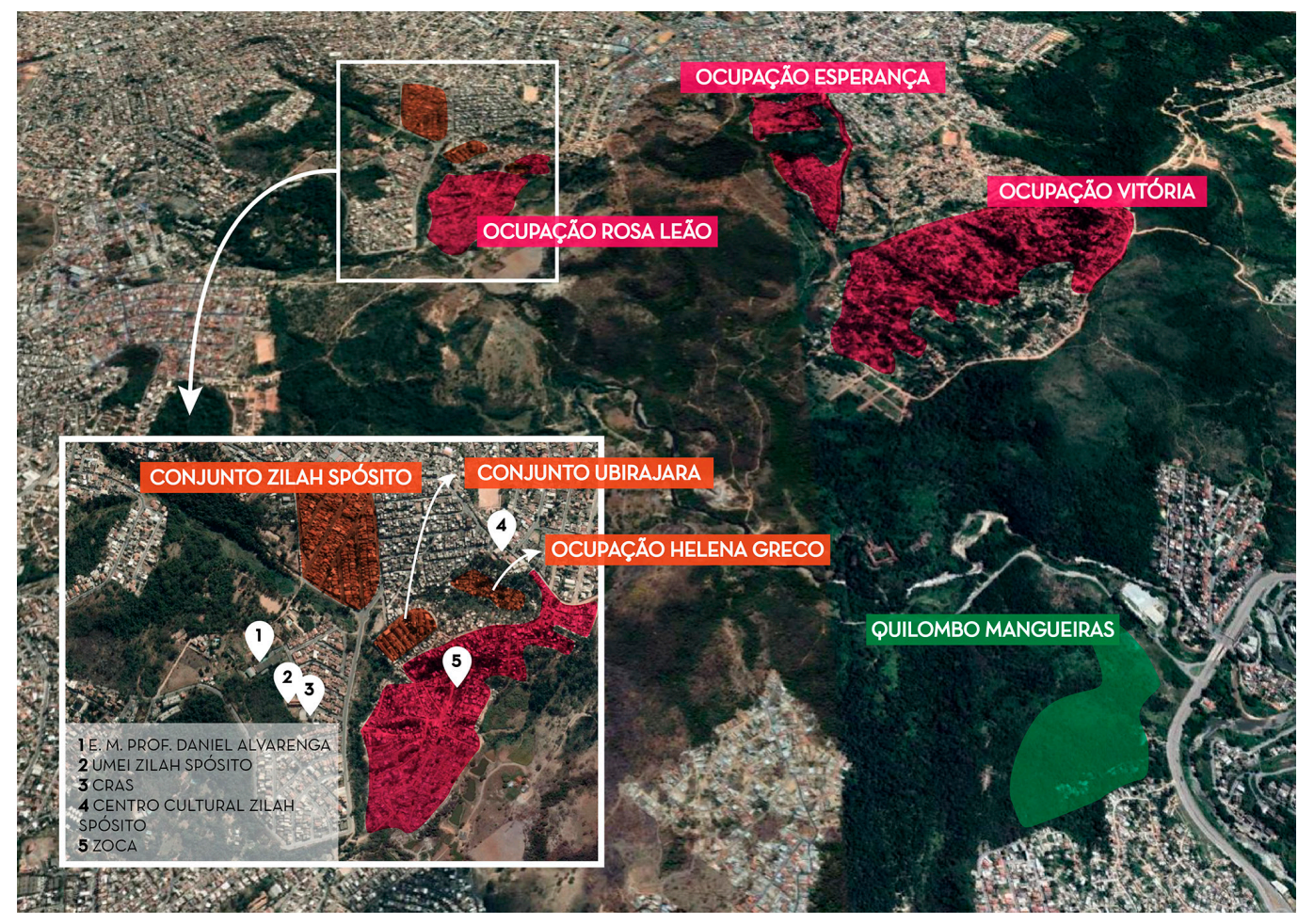

Figura 1. Região da Izidora

Fonte: Elaborado pela autora (SILVA, 2018).

\section{COMPLEXO DE DESENVOLVIMENTO URBANO CONTRA OS DIREITOS HUMANOS}

10 MEGAPROJETOS BI [MIJ LHONÁRIOS X 8.000 FAMILLAS

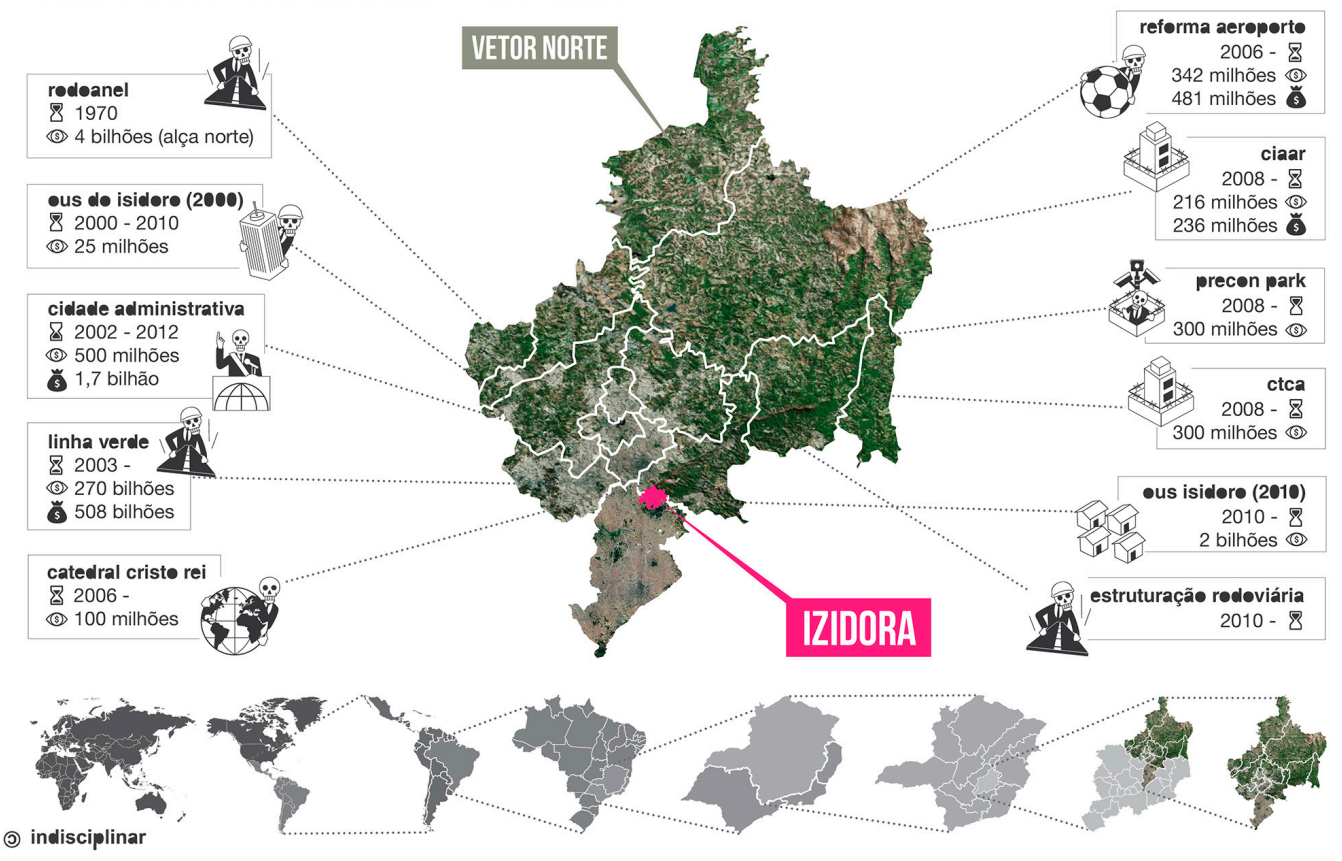

Figura 2. Megaprojetos previstos para a região da Izidora

Fonte: Mapa produzido por Julia Franzoni, Natália Alves da Silva e Daniela Faria para apresentação do caso Izidora no Tribunal Internacional de Despejos (2016), em parceria com o Coletivo Margarida Alves, com informações de Freitas (2016). 
Na região da Izidora, as histórias de milhares de pessoas que, em sua luta política diária, reconfiguram o espaço urbano se aproximam das memórias do Quilombo de Mangueiras e dos conjuntos de habitação social situados em seu entorno, como o Ubirajara e o Zilah Spósito. Percorro brevemente a cartografia do conflito para evidenciar as disputas de lugar que transcorrem desde o século XIX - período da provável fixação de Izidora da Costa na região que seria batizada com seu nome e da formação do Quilombo de Mangueiras - até a atualidade, quando se consolidam as três "ocupações da Izidora”. Por ora, proponho uma cartografia que evidencie a formação e a continuidade no tempo desses territórios negros e das lutas travadas contra os diversos níveis de violência do Estado-capital, que conformam tentativas contínuas de embranquecimento da área e do subsequente apagamento da agência de pessoas negras - e, em particular, das mulheres negras - na história da região.

Fundado pelo casal Vicência Vieira de Lima e Cassiano José de Azevedo, o Quilombo de Mangueiras situa-se no limite entre Belo Horizonte e o município de Santa Luzia, pertencente, até o final do século XIX, à Vila de Sabará. Essa área era chamada de "Ribeirão da Izidora". De acordo com a narrativa da comunidade, Izidora foi uma escravizada que, depois de receber a alforria, se estabeleceu na região. $\mathrm{O}$ fato de o seu nome ter batizado o ribeirão e a mata da região em que viveu constitui indício bastante forte da importância histórica dessa mulher negra que a associação Estado-capital tentou, sem sucesso, apagar - ou transformar em "Isidoro".

Já a história do Mangueiras é contada por seus moradores por meio da evocação do nome de outra mulher negra, Maria Bárbara de Azevedo (1863-1936), considerada a matriarca do quilombo por ter conseguido assegurar a posse de parte do território original da comunidade depois de sucessivas divisões realizadas por ordem judicial (NUQ-UFMG, 2008).

A comunidade se localizava às margens de grandes fazendas, para as quais seus membros trabalhavam como agregados e prestadores de serviços, enquanto mantinham a prática africana e afro-brasileira de uso coletivo do território. Cassiano e Vicência conseguiram o registro das terras que ocupavam, o que foi fundamental para a construção de sua identidade, a qual, por seu turno, fortalece a luta contemporânea pelo território do Quilombo de Mangueiras.

Se a localização do casal e seus filhos às margens da futura estrada que ligaria Santa Luzia a Belo Horizonte favoreceu a integração econômica do grupo na região, também provocou maior especulação e pressão imobiliária sobre suas terras, principalmente a partir da década de 1920. Nesse período, é edificada a referida via, e o médico carioca Hugo Werneck (que futuramente se destacaria como influente empresário da comunicação, banqueiro e político) dá início, com recursos obtidos junto 
ao Banco do Brasil, à construção da Granja Werneck, um sanatório voltado prioritariamente para o tratamento de funcionários da instituição (NUQ-UFMG, 2008).

Do ponto de vista da população do quilombo, uma das mais sérias consequências da construção do sanatório nas imediações foi o que passaria a ser definido como "racismo ambiental": em virtude da falta de esgotamento sanitário, os detritos dos pacientes eram jogados no ribeirão da Izidora, o que inviabilizava o uso da água pelos quilombolas tanto para o consumo diário como para o cultivo de alimentos e a realização dos ritos sagrados. O peso da crescente influência política, econômica e cultural dos Werneck pode ser percebido nos mapas oficiais das décadas seguintes, quando o Quilombo de Mangueiras se torna um "não lugar”, um "espaço vazio". O ribeirão da Izidora tem o nome alterado para "ribeirão do Isidoro" e o bairro ficou conhecido como Granja Werneck, num flagrante apagamento das geografias negras na região.

A partilha do território quilombola, que levou à individualização de vastas extensões de terra, desde sempre usadas coletivamente, contou com a participação ativa de um membro da família Werneck. Então gerente da Granja, Roberto Eiras Furquim Werneck foi o autor da ação que lhe permitiria adquirir metade da área do Ribeirão da Izidora, em 1932 (Figura 3). É válido frisar que, de acordo com o Relatório Antropológico (NUQ-UFMG, 2008), os documentos comprobatórios da transação nunca foram apresentados pelo suposto comprador.

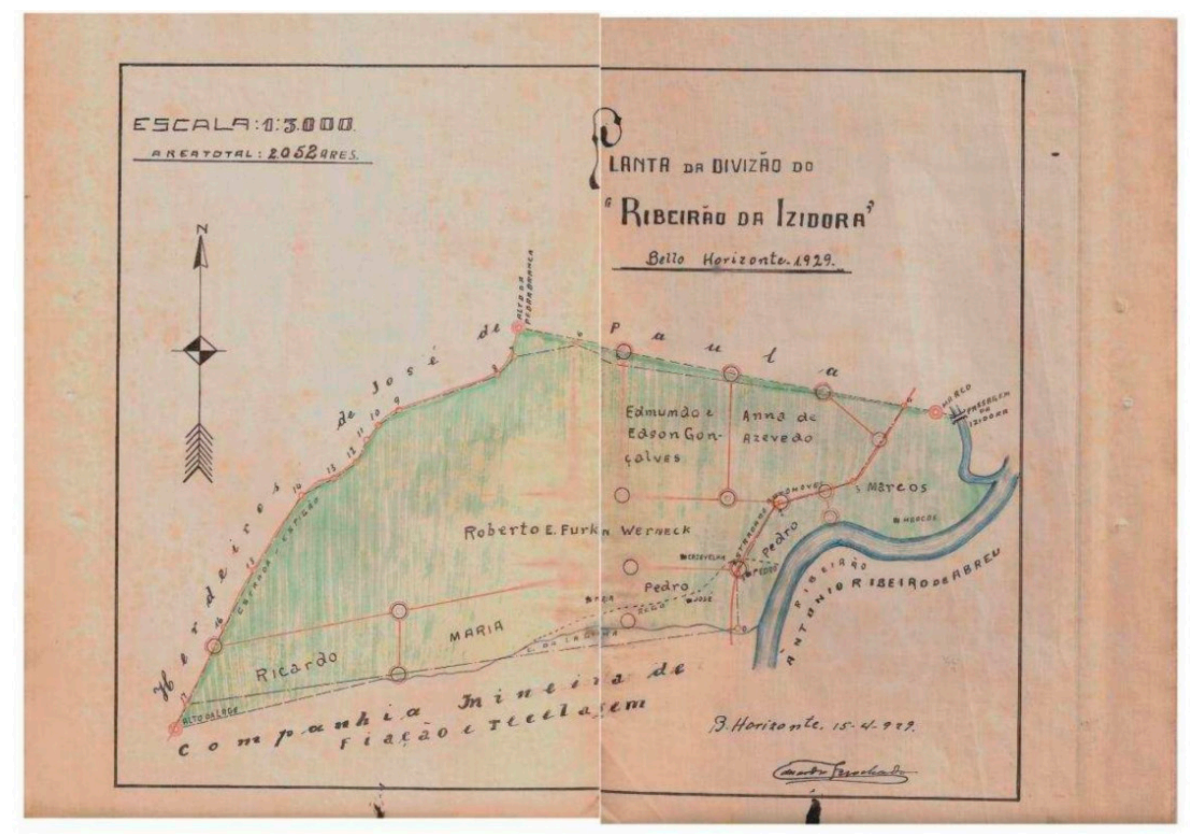

Figura 3. Planta de divisão do Ribeirão da Izidora (1929)

Fonte: Relatório Antropológico do Quilombo de Mangueiras (NUQ-UFMG, 2008). 
No final da década de 1990 e início dos anos 2000, foram elaborados novos planos de desenvolvimento do vetor norte, justificados pelo poder público em função da necessidade de conter frentes de ocupação desordenadas e a ameaça a áreas de proteção ambiental, além de aproveitar o crescente interesse do mercado imobiliário pela região. Para atrair investidores privados, é editada a Lei Municipal $n^{\circ} 8.137$ (BELO HORIZONTE, 2000), que altera o Plano Diretor de 1996 e estabelece a Operação Urbana do Isidoro (OUI), cuja área total é de cerca de $10 \mathrm{~km}^{2}$ (FREITAS, 2016, p. 177). O projeto não teve a adesão esperada do setor privado nem foi priorizado na pauta política dos prefeitos seguintes.

Dez anos depois, ocorre a reestruturação da Operação Urbana, com a proposição de um novo modelo urbanístico, igualmente voltado para as classes média e alta (FRANZONI; FARIA; RENA, 2016). O plano de 2010, que também não contou com a esperada adesão do capital privado, foi retirado da pauta de prioridade política do Executivo municipal. Surge uma terceira proposta em 2014 - o empreendimento Granja Werneck (EGW), projetado para ser um dos maiores conjuntos do Programa Minha Casa Minha Vida (PMCMV) do país, que tinha como objetivo a construção de mais de 13 mil unidades de moradia numa área equivalente à quase totalidade das três ocupações urbanas.

Ancorado na razão neoliberal, que a tudo tenta impor a forma-mercadoria, o projeto visava substituir o uso dado à terra, aos bens comuns e às atividades ali desenvolvidas pelo valor de troca estipulado pela Operação Urbana. O desrespeito às condições de vida das/dos moradoras/es da Izidora e do Quilombo de Mangueiras conformava uma verdadeira comoditização dos direitos (moradia, cidade, trabalho, entre outros), fundamental para a materialização do projeto de embranquecimento da região.

$\mathrm{Na}$ atualidade, das quatro ações judiciais referentes às áreas da Izidora, duas seguem vigentes: a ação movida pela Fazenda Tamboril e a ação de Ângela Werneck, que reivindica parte da área da ocupação Esperança. Por outro lado, as lutas acumuladas ao longo de seis anos conquistaram o reconhecimento das ocupações por parte do Executivo municipal e estadual, que as qualificaram como Áreas de Especial Interesse Social (AEIS-2), consubstanciado em um decreto de 12 de abril de 2018 (FRANZONI, ALVES, FARIA, 2020, p. 2). Em 2019, com a aprovação do novo Plano Diretor de Belo Horizonte, as mesmas áreas foram incorporadas à lei.

1. Os decretos foram comentados pela rede Resiste Izidora em: https://www.facebook.com/ notes/resiste-izidora/para-compreender-melhor-os-dois-decretos-do-prefeito-de-belo-horizonte-alexandre/1383434508469189/. Acesso em: 20 jan. 2020. 
As várias versões da Operação Urbana reeditam uma série de características já identificadas em outros grandes projetos urbanos, notadamente a aproximação entre a agenda urbana e os interesses de agentes imobiliários. Freitas (2016) assinala que a novidade trazida pela Operação Urbana Isidoro é o papel do planejamento urbano, não só no esvaziamento conceitual do projeto, como em sua subversão, com a centralidade das agendas externas.

Encerro esta seção do artigo com uma breve menção a duas conquistas dos territórios negros da região da Izidora que atestam a importância das lutas de sua população pelo direito à vida plena: a emissão da certidão de autorreconhecimento da Comunidade de Mangueiras como remanescente dos quilombos, em 2005, e, em 2018, a atribuição ao quilombo, pelo Conselho Deliberativo do Patrimônio Cultural de Belo Horizonte, da condição de patrimônio cultural. Lidos em perspectiva relacional, esses dois atos técnicos e administrativos, embora distantes no tempo, se complementam como gesto político e apontam para a possibilidade de superação da tendência à dissociação entre cultura e espaço, que tanto apraz ao Estadocapital, como se as “manifestações culturais” pudessem existir sem a materialidade do território e das relações sociais nele consubstanciadas.

Na seção que segue, mostro como as violências físico-territoriais se coadunam com a produção de inexistência nas leituras do urbano mobilizadas contra os mesmos grupos subalternizados. Também argumento sobre os ganhos epistêmicos de abordagens que consideram as dimensões de gênero e raça na leitura das disputas espaciais.

\section{Perspectiva interseccional na leitura do espaço}

A ação do poder público na região da Izidora, conforme exposto, teve como intuito promover o total apagamento dos territórios negros pelo recurso à violência física, por meio de coerções ou pelo uso da violência epistêmica, que se manifesta, por exemplo, nos atos de supressão das nomeações dadas ao território por sua população. O Estado-capital buscou substituir o uso dado à terra, aos bens comuns e às atividades ali desenvolvidas pelo valor de troca e pelo embranquecimento do território (SANTOS, 2019).

Está em discussão a necessidade de entender os mecanismos implicados no despejo como co-constituídos pelas relações de gênero e raça. Para além do reconhecimento do efeito diferencial nos corpos, as resistências no território combinam diversas práticas do espaço e grafias espaciais (SANTOS, 2018), em que categorias baseadas exclusivamente na economia política do conflito não são suficientes para captá-las. Nos estudos urbanos, há o predomínio de leituras que invisibilizam as dimensões de gênero e raça. Susan Smith (1996, p. 255) aponta que as estruturas 
mobilizadas para entender o urbano são partes de generalizações, para toda a população, da experiência dos homens - brancos, acrescento.

Inicialmente será discutido como a exiguidade de estudos urbanos sobre o protagonismo das mulheres negras integra os processos de violência epistêmica contra a população negra e demais grupos subalternizados. Em seguida, nosso foco se volta para o modo como esse apagamento tem sido combatido em algumas literaturas sobre o tema e, finalmente, para os desafios metodológicos e minhas próprias contribuições para a leitura do caso estudado neste artigo.

Inúmeros artigos apontam a presença massiva de pessoas racializadas, em especial mulheres negras, nos territórios em disputa. Marinho, Rolnik e Lins (2018) notam que sujeitos negros são os mais impactados pelas ações de remoções na Região Metropolitana de São Paulo. Almeida e Franco (2018) citam o impacto diferencial do desabrigamento no cotidiano das mulheres. Soraggi e Aragão (2016) observam o papel por elas desempenhado na organização das atividades coletivas em uma ocupação urbana de Belo Horizonte. No entanto, para além de constatações pontuais, ainda hoje há poucos trabalhos em que gênero e raça estejam na centralidade do debate. Sobre a Vila Autódromo, palco de forte resistência à política remocionista da Prefeitura e do Governo do Estado do Rio de Janeiro em função dos megaeventos de 2014 em torno da Copa do Mundo, há vasta bibliografia que enfatiza a nova política gentrificadora do poder público (CALDAS, 2017), os instrumentos de política urbana mobilizados na resistência (SÁNCHEZ et al., 2016) e a construção do conceito de planejamento conflitual para o caso (OLIVEIRA; TANAKA; COLI, 2019). Entender como o conflito foi atravessado pelas dimensões de gênero (MONTEIRO; MEDEIROS; NASCIUTTI, 2017) e raça é um desafio importante, que tende a enriquecer os estudos urbanos.

Certa literatura feminista, no tocante ao planejamento urbano, tem discutido os despejos sob a ótica da "acumulação por despossessão" (HARVEY, 2016), como chave analítica potente para evidenciar experiências de cercamento de terra que ameaçam a vida com impactos desiguais para mulheres e pessoas negras (SOBRINHO, 2007; HARKOT, 2019; LACERDA et al., 2020). Em Franzoni, Alves e Faria (2018, p. 3), argumentamos que "a acumulação por despossessão não é um fenômeno abstrato" e que sua concretude põe em risco territórios e todas as formas de vida nele existentes, além de produzir e reforçar o racismo, a desigualdade socioespacial e o heterocispatriarcado.

Ao propor uma "poética feminista negra", Denise Ferreira da Silva (2019) figura o capital como uma arquitetura jurídico-econômica com diferentes métodos de expropriação ou apropriação de territórios e de trabalho, quer por meio de acordo legal (exploração), quer por coerção física, o que leva à apropriação 
do valor-total criado. Para essa filósofa, o conceito de acumulação por expropriação pode prestar-se à figuração da trajetória pós-escravidão dos negros e negras na América, marcada por exclusão econômica e alienação jurídica - escravidão, segregação, encarceramento em massa -, que deixaram uma percentagem desproporcional da população negra economicamente despossuída (CHAKRAVATTY; FERREIRA DA SILVA, 2013).

Na Izidora, em vários momentos, verificou-se a organização do Estado para o emprego da violência total contra as ocupações. As coordenações das três ocupações, em conjunção com integrantes da rede de apoio, produziram um dossiê sobre as arbitrariedades cometidas pela Polícia Militar, apresentado em reuniões e audiências públicas e encaminhado ao Superior Tribunal de Justiça, que concedeu medida liminar para suspender qualquer ação que viesse a culminar no despejo dos moradores (FRANZONI, 2018).

Lao-Montes (2019) contesta o modo hegemônico de leitura no campo do urbanismo. Em um contexto no qual a cidade equivale ao "moderno", o "afro" ou "negro" representa as margens, as classes e os lugares perigosos, primitivos, insalubres, indesejados e exotizados. Lélia Gonzalez (1982) interpela a naturalização do que define como "divisão racial do espaço”. Em apelo que reverbera o de Sueli Carneiro, de "enegrecer o feminismo”, Lao-Montes chama a atenção para a necessidade de enegrecer o pensamento sobre as cidades (LAO-MONTES, 2019, p. 1).

Há muitos desafios na construção de metodologias capazes de captar as lutas geográficas protagonizadas por mulheres negras. No caso da Izidora, registrei em cadernos de campo as histórias compartilhadas comigo pelas mulheres que participavam mais ativamente do movimento. Atuei na rede de apoio desde os primeiros dias da ameaça de despejo, ao mesmo tempo que coordenava ações formativas (oficinas e rodas de conversa). Também me empenhei em tentar compreender quem foi Rosa Leão, por meio de diálogos informais com as moradoras mais antigas do Conjunto Ubirajara, vizinho da Ocupação. Essas conversas, que me levaram à formulação de um método, me permitiram obter indícios sobre Izidora, uma mulher negra que teria vivido na região que hoje leva seu nome. Tecia-se dessa maneira uma trama que aproximava a vida de três mulheres negras que, em três tempos históricos diferentes, davam a ver formas distintas de relação da população negra com as disputas de lugar e a luta pelo território.

Patricia Hill Collins (2000) aponta o método narrativo como um dos traços fundamentais de uma epistemologia feminista negra. Esse método, que emerge do deslocamento do locus epistêmico na produção da teoria e questiona os critérios hegemônicos de produção e validação do conhecimento, uma vez que se assenta na 
experiência vivida como critério de significação do mundo, tornou-se a base a partir da qual busquei captar a rica e complexa paisagem da vida social negra na Ocupação.

Minha condição de pesquisadora que descende de uma família formada por pessoas negras, pobres e migrantes não me deixava a opção de uma escuta pretensamente isenta. Segundo Hartman (2020, p. 18), "a escrita é pessoal porque essa história me engendrou, porque o conhecimento do outro me marca”. Tudo me parecia familiar. Construímos, assim, sólidas pontes dialógicas a respeito dos assuntos da Ocupação, das histórias individuais e coletivas e das lógicas de produção e circulação do conhecimento acadêmico. Eu me vi dentro do "lugar especial" que Collins (2016) define como aquele ocupado por intelectuais negras e outros grupos marginalizados em contextos acadêmicos como outsider within, ou "forasteiro de dentro". Essa definição aponta para o fato de que, em oposição à marginalidade a que estamos submetidas, a qual gera desajustes entre os paradigmas hegemônicos da produção do conhecimento acadêmico e nossas experiências, o status de outsider within assinala uma posição de estímulo à criatividade e à crítica, assentadas na conjugação entre o treinamento acadêmico e a experiência vivida.

A construção dessa trama trans-histórica demandou algumas escolhas. Sobre Izidora, como só me foi possível encontrar algumas informações de arquivo, que se somaram a relatos orais de moradores mais antigos da região, recorri ao exercício da "fabulação crítica", procedimento conceitual e técnico formulado pela escritora estadunidense Saidiya Hartman (2020), que permite "deslocar o relato preestabelecido ou autorizado e imaginar o que poderia ter acontecido” (HARTMAN, 2020, p. 29).

Das muitas horas de conversas gravadas sobre a trajetória de Rosa de Jesus Leão, escolhi reproduzir partes da interlocução com Marlene de Mattos, que foi sua amiga íntima, parceira na lida cotidiana, nos embates políticos e na plena vivência do direito à farra e ao prazer. $\mathrm{O}$ depoimento de Marlene nos permite pensar nas dimensões do cotidiano e da formação do afeto nos processos de luta, numa ampliação do escopo do político - impensável, sob uma perspectiva convencional.

Charlene Egídio nos fala sobre a Ocupação Rosa Leão ancorada no legado ético e político deixado pelas lutas de mulheres negras na região e nos processos de construção comunitária. Formada politicamente nos embates contra o autoritarismo do Estado-capital, Charlene faz uma detida análise do contexto em que se organiza esse importantíssimo capítulo da luta pelo território em Belo Horizonte.

Essas narrativas fragmentárias complementam-se e ajudam a compor o multifacetado quadro das lutas pelo território no Brasil. Se o fragmento é o que resta de um texto (escrito ou falado), podemos tomá-lo, também, como uma das partes fundantes do testemunho coletivo - do qual fazem parte o esquecimento e a 
incompletude - sobre alguma informação que não se quer e não se pode perder. Recorro à Leda Maria Martins (1997), que denomina oralitura os atos de fala e performance, os quais compreendem a singular inscrição do registro oral que, como letra, grafa o sujeito num dado território narrativo e enunciativo.

As disputas por território na narrativa que se segue envolvem tanto "uma identidade territorial atribuída pelos grupos sociais" como "a apropriação e ordenação do espaço”, em que predomina o valor de troca (HAESBAERT, 2020, p. 94). Ciente de que são chamadas para essa conversa autoras que se privilegiam a categoria "lugar", como Katherine McKittrick, faço uso dessas duas categorias para expressar as narrativas sobre Izidora. Territórios negros, aqui, são concebidos como "espaço físico e simbólico, configurado a partir da funcionalidade e/ou da prática cultural em que a presença negra, embora possa não ser exclusiva, é uma questão central” (VIEIRA, 2017, p. 43).

Durante o processo investigativo, foi nas rodas de conversa que ocorreram a aplicação prática e a ampliação do método narrativo. Destaco a oficina cartográfica (Figuras 4 e 5), em que recuperamos narrativas individuais e coletivas sobre a Ocupação, com o propósito de gerar um dispositivo que permitiu à coordenação discutir com moradores mais recentes, apoiadores e poder público as histórias das disputas espaciais travadas em Rosa Leão. Essas trocas também foram alimentadas pelas oficinas de construção civil para mulheres (Figura 6), que se tornaram um espaço-tempo de aprendizado mútuo e discussões potentes (SILVA, 2018; CRUZ; SILVA, 2019).

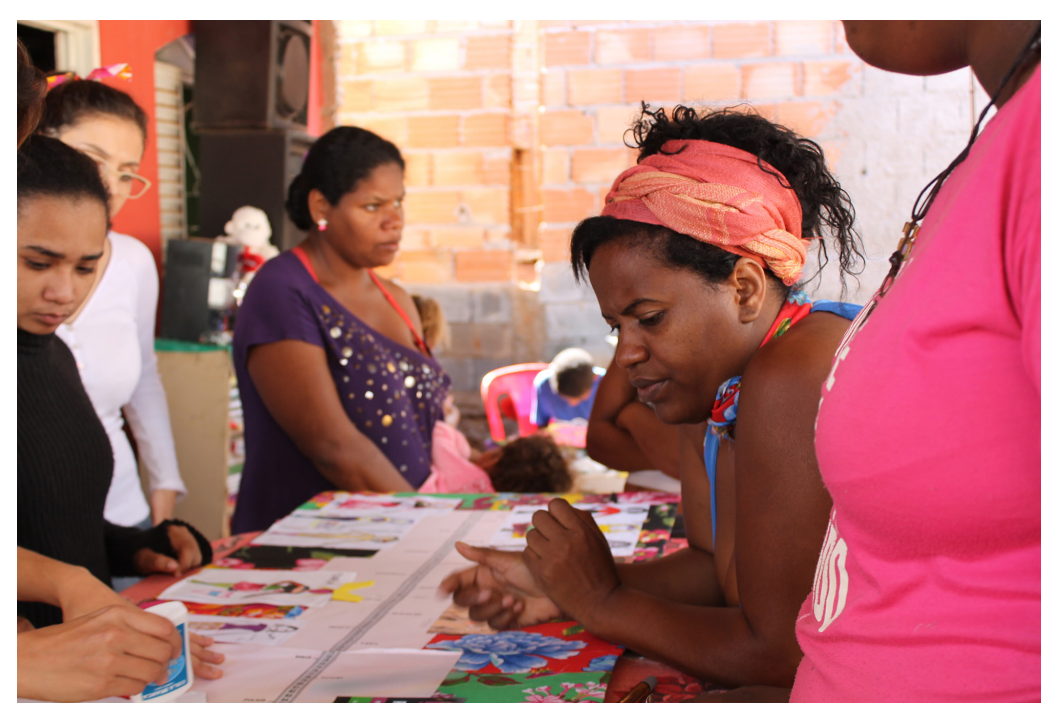

Figura 4. Oficina cartográfica na Ocupação Rosa Leão Fonte: Arquivo pessoal da autora (2017). 


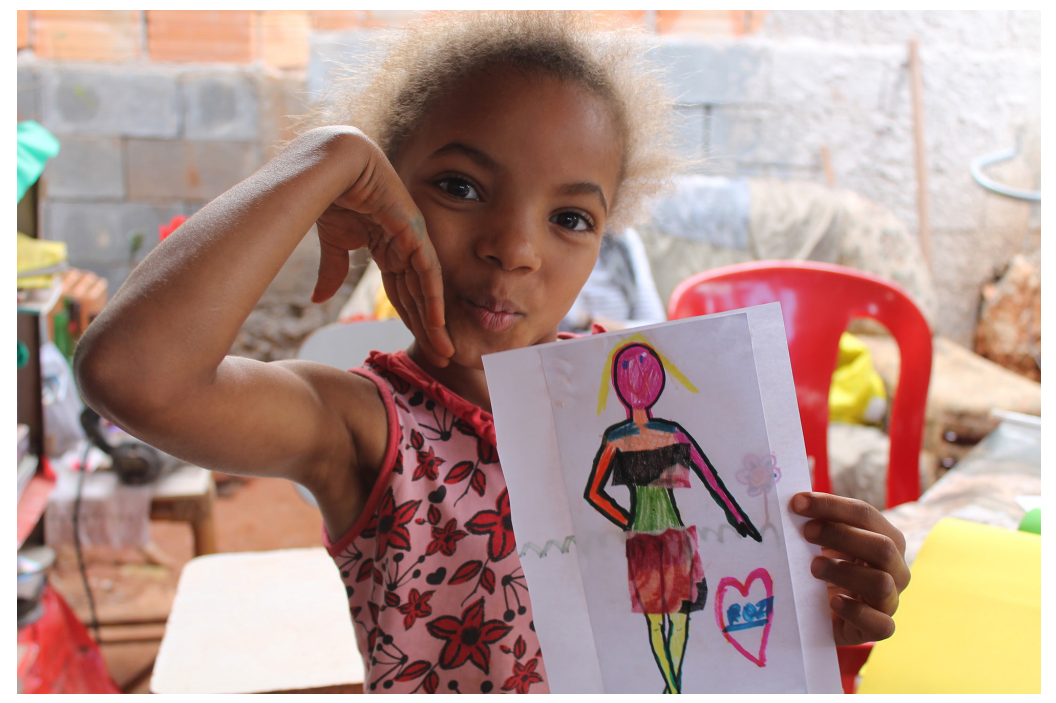

Figura 5. Detalhe da oficina cartográfica na Ocupação Rosa Leão apresentado por Sara dos Santos Fonte: Arquivo pessoal da autora (2017).

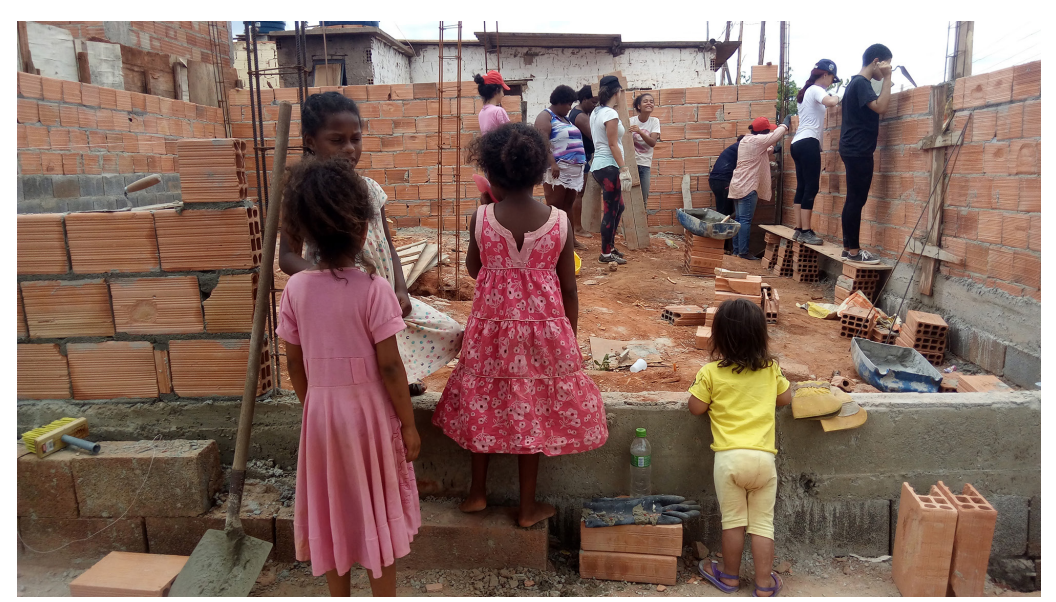

Figura 6. Oficina de construção para mulheres na Ocupação Rosa Leão Fonte: Arquivo pessoal da autora (2017.

Uma abordagem interseccional das práticas espaciais na cidade se aproxima do que McKittrick (2006) define como geografias negras. Nesse modelo conceitual, as histórias negras estão ligadas entre si pelos modos como respondem à dominação geográfica. Desse modo, as geografias negras fazem emergir padrões alternativos que trabalham ao lado e além das geografias e locais tradicionais (McKITTRICK, 2006, p. 17).

De acordo com Mara Viveros (2016), a aposta na interseccionalidade nos permite apreender as relações sociais como construções simultâneas em diferentes ordens, de classe, gênero, raça, sexualidade, e em diferentes configurações históricas ou "realizações situadas, [...] contextos em que as interações de raça, classe e gênero atualizam essas categorias e lhes dão seus significados” (VIVEROS, 2016, p. 12). 
Nas seções seguintes, são apresentadas narrativas de pesquisa das disputas de lugar vivenciadas por Izidora da Costa, Rosa de Jesus Leão e Charlene Egídio que me permitiram propor novas leituras sobre o conflito da Izidora, e, em particular, sobre as práticas do espaço na Ocupação Rosa Leão. Mostra-se desse modo como as geografias presentes e passadas, embora distintas e particulares, se enredam nesses três casos.

\section{Uma Izidora e duas Rosas}

3. 1. Izidora

Nas investigações de arquivo a que recorri para tentar entender quem foi Izidora, defrontei-me com mais um exemplo de como se invisibilizam as vidas negras, que são reduzidas a um rol mínimo de informações fragmentadas. Hartman (2019) observa que pesquisadoras comprometidas com as narrativas de pessoas negras são forçadas a "lutar contra o poder e a autoridade do arquivo e os limites que ele impõe ao que pode ser conhecido, qual perspectiva importa e quem é dotado da autoridade do ato histórico" (HARTMAN, 2019, p. xiv).

Compreendi que, se tudo o que minha pesquisa lograra alcançar a respeito de Izidora eram fragmentos escassos acerca de quem terá sido essa mulher cujo nome figura nas memórias de quem vive na região e nos mapas mais antigos de Belo Horizonte, era com essa exiguidade (produzida social e politicamente) que eu teria que lidar. O escasso, o parco, o mínimo, afinal, sempre fizeram parte da minha vida - como filha e neta de mulheres negras que, com o pouco que sabiam, em termos de instrução formal, tanto me ensinaram no tocante à produção do conhecimento.

Até pelo menos 1937, o ribeirão que dava nome à área constava nos mapas de Belo Horizonte como ribeirão da Izidora ${ }^{2}$. Nos mapas posteriores, a grafia passa a ser Isidoro, e a região recebe o nome de Mata do Isidoro. A masculinização do nome foi recebida por nós, que formávamos a rede de apoio, e pelas coordenadoras das ocupações como uma questão relacionada ao machismo estrutural e estruturante, que tem no apagamento da presença das mulheres no mapa e na história um de seus grandes trunfos. Ao entrar em contato com o Quilombo de Mangueiras, tomamos conhecimento de que, segundo a narrativa da comunidade, Izidora foi uma escravizada que, depois de alforriada, se estabeleceu na região e ali constituiu sua descendência ${ }^{3}$. Perguntava-me, todo o tempo, se teria ocorrido algum tipo de

2. O ribeirão da Izidora, principal afluente da Bacia do Onça, ganha esse nome em sua homenagem. (BORSAGLI, A. Rios invisíveis da metrópole mineira. Belo Horizonte: Ed. do Autor, 2016).

3. A primeira pessoa a levantar essas informações foi a pesquisadora Margarete Leta, integrante da Associação dos Arquitetos Sem Fronteira e professora da Pontifícia Universidade Católica de Minas Gerais (PUC-MG) e da Universidade Federal de Minas Gerais (UFMG). 
intercâmbio entre a gente da Izidora e os quilombolas. E, ainda, se Vicência e Cassiano, e, por extensão, o Quilombo de Mangueiras, poderiam fazer parte da descendência de Izidora da Costa.

Na pesquisa, encontrei dois registros oficiais em que há referências ao nome Izidora. A primeira está no Registro de Terras do Curral Del Rei, arraial anterior à construção da cidade de Belo Horizonte ${ }^{4}$. Nele, figura certa Izidora da Costa como possuidora de meio alqueire de terras no Ribeirão do Onça (Venda Nova), que fazia divisa com a propriedade dos herdeiros de João Antonio da Silva e de Jozé Vieira e com o Ribeirão Acima. As informações foram declaradas e registradas em $28 \mathrm{de}$ março de $1856^{5}$. É importante notar que a área indicada como de propriedade de Izidora faz parte da mesma região hoje chamada de Mata do Isidoro.

A outra informação refere-se à escrava forra Maria Izidora, de 38 anos, arrolada entre escravizadas e escravizados do coronel Luis da Siqueira, residentes na região denominada Palmital, na então Freguesia de Nossa Senhora da Boa Viagem de Curral Del Rey. Esses dados constam da Lista de Habitantes datada de $1828^{6}$.

Diante dessas informações, que compunham aos poucos a imagem de uma mulher negra proprietária de terras num contexto de despossessão da população negra ex-escravizada, novo sortimento de perguntas se impôs: E se se tratasse da mesma pessoa? Poderia Maria Izidora ter se valido da condição de forra para conseguir os recursos necessários à aquisição de suas terras? Como terá feito para registrá-las, de acordo com a controversa Lei de Terras de $1850^{7}$, a fim de garantir o direito de seus descendentes? Como e quando teria passado a assinar da Costa? Sobre a possível origem de seu sobrenome toponímico, especulo: Onde seus ancestrais podem ter nascido e vivido? Que costa seria essa a que seu nome faz menção? A Costa do Ouro de coromântis, fântis, assantes ou mina, atual Gana? Ou o distante Moçambique, de onde, entre 1811 e 1830 , foram sequestrados $20 \%$ do total de escravizados que desembarcaram no Rio de Janeiro? (MAGALHÃES, 2010) De quem, senão dos integrantes de um grupo social ligado, como a própria Izidora, à ideia de ancestralidade - que implica uma noção de temporalidade circular -, teria partido a ideia de dar o nome dessa mulher a um ribeirão?

\footnotetext{
4. Belo Horizonte foi fundada em 12 de dezembro de 1897 como cidade planejada que buscava seguir os moldes modernistas de Haussmann.

5. Cf. APM - FUNDO REPARTIÇÃO DE TERRAS PÚBLICAS. Transcrição do Livro TP-1-067 Nossa Senhora da Boa Viagem do Curral Del Rei (1855-1857). Registro nº 84. p. 32-33.

6. Essa lista foi publicada em TASSINI, R. Verdades históricas e pré-históricas de Belo Horizonte antes do Curral Del Rei. Belo Horizonte: [s. n.], 1947. (Acervo da Biblioteca do Arquivo Público Mineiro).

7. "Na verdade, ela [a Lei de Terras] nasceu como instrumento legal que assegurava um monopólio de classe sobre a terra em todas as regiões do país, mesmo naquelas ainda não ocupadas economicamente" (MARTINS, 1979, p. 155). MARTINS, J. S. O cativeiro da terra. São Paulo: Livraria Editora Ciências Humanas, 1979 .
} 
Contíguo à Ocupação Rosa Leão, o Conjunto Ubirajara é composto de cem sobrados (HOURI, 2008). Antes de se instalarem definitivamente no Conjunto, as/ os moradoras/es ocuparam uma área no limite entre os bairros Itatiaia e Santa Terezinha, na região da Pampulha. Instalada nas margens do córrego homônimo em 25 de abril de 1994 (ROSA, 2010), a Ocupação Sarandi contou, em sua origem, com cerca de sessenta famílias (URBEL, 2000).

Rosa de Jesus Leão morou na Sarandi e ali integrou o Movimento de Luta por Moradia (MLPM) como uma das representantes do grupo nas mesas de negociação. O acordo foi fechado com o então prefeito de Belo Horizonte, Patrus Ananias (PT), no final de 1994. As famílias do Sarandi que cumpriam os critérios estabelecidos pela política habitacional do município e conseguiram resistir aos meses de espera ${ }^{8}$ foram removidas para uma área de propriedade da Companhia Urbanizadora de Belo Horizonte (Urbel), no bairro Jaqueline, com o compromisso de construção de suas moradias. Daquele momento em diante, seguiram-se quatro anos de teto de lona e de luta até o término das obras - realizadas por empreiteira contratada pela Urbel - e a inauguração do Conjunto, em $1998^{9}$.

Marlene de Mattos recebe o grupo em sua casa no Conjunto Ubirajara. Entusiasma-se com a proposta de recontar a história de Rosa e, enquanto fala, procura fotos em uma sacola. A contemplação das fotos ativa suas lembranças e presentifica temporalidades que se atravessam e, no instante irrepetível do diálogo, relativizam as diferenças entre o tempo do afeto e o da luta e compensam a exiguidade de documentos à disposição da pesquisadora.

Eu gosto muito de falar nela, que vêm as coisas todinhas, a dificuldade que a gente passou nas barracas de lona, o sofrimento que a gente passou junta. [...] A gente tinha uma amizade, eu e a Zoca e a Rosa, que a gente era muito assim, a gente bebia junto, dançava forró junto. A Rosa gostava era de uma cachaça. A gente ia pra casa dela, ela ia no açougue, ela arrumava umas coisas lá[,] a gente fritava e bebia. Ela gostava de casa cheia. Tinha sempre gente na casa dela. Você podia chegar na casa dela qualquer hora que sempre tinha gente. Procurando ela pra doação de cesta básica, alguma coisa que ela fazia, ela tava sempre envolvida com alguma coisa na comunidade. Não tinha quem não conhecesse a Rosa. Todo mundo conhecia a Rosa.

8. O critério principal era ser de Belo Horizonte. Isso excluiu as famílias participantes originárias de Contagem.

9. Para mais informações sobre a política habitacional de Belo Horizonte no período, cf. BEDÊ, M. C. Trajetória da formulação e implantação da política habitacional de Belo Horizonte na gestão da Frente BH Popular 1993/1996. 2005. Dissertação (Mestrado) - Instituto de Geociências, Universidade Federal de Minas Gerais, Belo Horizonte, 2005. 
Ela era uma pessoa extremamente do povo, ela ajudava muito. Igual assim, alguma coisa tem dela na Charlene. Ela era muito solidária. Eu falava com ela assim que ela tinha muita sensibilidade e muito coração. A gente parecia. A gente já brigou, sabe? Eu lembro que antes dela morrer a gente tava meio brigada. Aí a gente ficou mais ou menos um mês sem falar. Aí no dia do meu aniversário, ela tava sentindo a minha falta. Eu lembro até hoje. Aí ela ligou no meu fixo, eu morava no bloco 9 ali. Aí mandou a Estela falar uma mensagem linda para mim no telefone, aí na mesma hora eu fui abraçar ela. "Eu gosto demais d'ocê. Não consigo ficar sem ocê não, sô." Ela me disse assim que "tô passando uma fase dificil com meu companheiro, o Juninho", falava que era o pai do Ítalo. Aí ela falou "vamos marcar de beber, beber nós juntas". Então vamo marcar sexta-feira. Eu saio do serviço e a gente encontra lá naquele buteco lá, um butequinho na Rio de Janeiro com Santos Dumont. Eu trabalhava num motel ali na Tupinambás, o Stillus. Eu disse, a gente marca lá, umas 16h, 16h3o. Eu te espero lá. A gente toma uma cerveja e conversa. A gente marcou e logo depois aconteceu a tragédia. [Rosa foi assassinada com um tiro no rosto em 2002, deixando cinco filhos que ficaram aos cuidados de Marlene e Zoca até se mudarem do Conjunto.]

Nota-se no relato de Marlene uma posição assumida pelas duas amigas que expressa quanto são redutoras as noções dicotômicas de público e privado. A amizade delas, que não se restringe ao âmbito privado, ao qual o patriarcado historicamente relega as mulheres, ousa "ocupar" o centro da cidade, num gesto político que recupera e amplia os múltiplos sentidos da presença das mulheres negras do passado e do presente no espaço urbano (Figura 7).

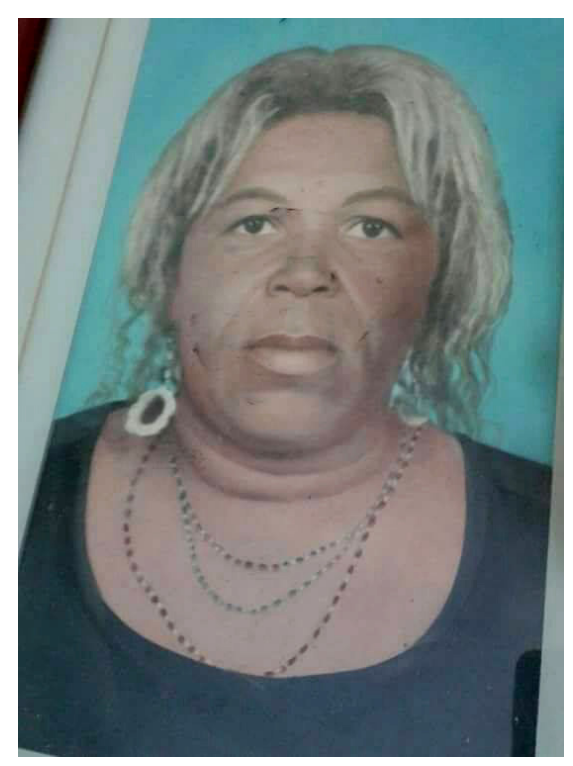

Figura 7. Retrato de Rosa de Jesus Leão Fonte: Arquivo pessoal da autora (2017) 
O trânsito de Marlene e Rosa entre as atividades de militância, o cuidado e a autodefinição permite pensar sobre como a construção da feminilidade negra "perturba as categorias de gênero normalizadas (masculino - agressivo, feminino - passivo, masculino - público, feminino - privado), que se baseiam na brancura” (McKITTRICK, 2006, p. 47). Não um local inocente de passividade e respeitabilidade privada nem um eu totalmente público e/ou racional, mas uma coleção de roteiros ideológicos que coloca em evidência uma complicada geografia corporal, definida por Santos (2018) como "geo-grafias”, ou seja, as formas pelas quais "as relações raciais grafam o espaço”, instituindo "territorialidades temporárias associadas a um pertencimento racial” (SANTOS, 2018, p. 77).

[Rosa] não sabia ler nem escrever. Mas conversava tão bem [...] mas você precisa de ver ela em reuniões assim, como ela conversava bem, como ela falava bem com as pessoas. Como ela articulava. Ninguém sabia que ela era analfabeta, de tão inteligente que ela era. Foi uma guerreira. [Rosa foi] muito importante para nós porque até hoje está na história, né? Acho legal, igual a Charlene fala assim que é uma pessoa que esses movimentos ela tava em tudo, negócio de mulheres ela tava assim, preconceito contra as mulheres ela sempre tava, para a mulher ter mais espaço.

O depoimento de Marlene é muito importante porque, além de nos apresentar uma Rosa que parecia não separar a luta (coletiva) pelo direito à vida do direito à fruição do bem viver, nos revela a dona de uma inteligência política tão rara que “(n)inguém sabia que ela era analfabeta”. Esse relato nos leva a pensar no trabalho silencioso (silenciado?) que inúmeras intelectuais negras, a despeito de sua condição de "analfabetas", desenvolvem diariamente, da hora em que saltam da cama até o instante, já quase outro dia, em que a fadiga as conduz a umas poucas horas de sono. Como não ver que tais mulheres, ao mesmo tempo que viabilizam suas vidas e as de quem delas depende, fazem de suas ações cotidianas modos sempre novos de pensar e recriar o mundo?

\subsection{E a Rosa}

Charlene Egídio nos fala sobre a formação da rede Resiste Izidora.

Olha, depois que aconteceu as ocupações, as outras duas ocupações, os mesmos movimentos que estavam aqui começaram a ir pra lá. Como começou o [movimento] Resiste Izidora? A partir do momento que a juíza da Vara Municipal pegou todos os processos da... Pegou o processo da Rosa Leão, da Esperança e do Vitória e juntou num só processo. Não poderia ter feito isso, mas a juíza fez pra despejar todo mundo. Como ela já fez esse bolo, a gente também fez o bolo na resistência, que aí colocar... Aí foi entender, foi saber da história do terreno, foi saber 
que toda essa região é Izidora, porém com proprietários distintos. E aí que foi entender esse processo e aí virou uma só grande ocupação, com três territórios separados. [...] assim como a juíza foi estratégica de juntar todo o processo pra despejar todo mundo de uma vez por interesse do capital e dos proprietários, nós também tivemos a estratégia de juntar todo mundo pra poder se resistir contra isso. Juntar as três comunidades, as três lideranças e também, uma vez que era o mesmo movimento nas três ocupações né?

A rede de luta Resiste Izidora, articulação e plataforma política criada em 2014 (inicialmente com o nome Resiste Isidoro), se constituiu em torno da agenda de resistência das ocupações urbanas, enredando comunidades, movimentos sociais populares e diversos apoiadores numa experiência de resistência que traduz a força das lutas urbanas na disputa pela cidade.

Santos (2006) destaca como a construção do ator em luta pode ter sua espacialidade definida por seu antagonista. Essa redefinição pode constituir um ator em escala compatível com a do antagonista, buscando interlocuções que fortaleçam sua luta. A espacialidade do interlocutor - no caso, a junção dos três mandados de despejo pela Justiça - e a dimensão da Operação Urbana Isidoro, que englobava as três ocupações, condicionaram a reconfiguração organizativa das lutas, contribuindo para a constituição dos territórios como ocupações da Izidora com "abrangência espacial compatível com o projeto” (SANTOS, 2006, p. 187) e identidade correspondente à ancestralidade negra do território.

É várias resistências durante os processos, não é só resistência do despejo. Primeiro é resistir com um grupo individualista que queria ocupar seu pedacinho só pra eles, que estavam acomodados e aí é isso, não deixa o resto ocupar. A outra questão foi resistir contra a especulação imobiliária territorial, resistir contra isso e também resistir dentro de um espaço que, no início, era sem lei, e [era difícil] pra você conscientizar a galera da questão ambiental, estrutural e urbanística do local. Isso foi uma outra resistência, assim, a pessoa entender que ela não vai chegar aqui de avião, que ela precisa de uma rua. A pessoa entender que precisa do verde, porque em vários processos, além da vida mesmo, da gente viver melhor, tem a questão de crime. Aí teve essa segunda resistência, que eu achei muito foda. Aí vem a resistência de você morar num lugar sem água, sem luz, sem saneamento, sem direito à escola, [exposto a] carrapato, bicho, cobra, aranha, essa é uma outra resistência. E poucas pessoas, porque a grande maioria vinha, cercava e ia embora, os poucos que ficaram no início é que resistiu nisso aqui. Que era gato pingado, eu posso falar pra você quantas pessoas moravam aqui nessa quadra. Aí, com muita luta, de falar: "Se não morar vai perder..." e a coordenação fazendo esse papel, $e$ quem morava tinha mais legitimidade pra fazer isso, é que avançou, então foi outra resistência. 
Charlene Egídio revelou-se, na conversa que tivemos, uma analista atenta do contexto geopolítico em que o movimento se formou e se consolidou. Suas elaboradas considerações críticas eram tecidas enquanto ela cozinhava o almoço, o que nos remete à questão da produção de conhecimento, do ponto de vista das mulheres negras, como uma tarefa tão inadiável e urgente quanto os cuidados com a casa e o bem-estar do grupo familiar - pelo qual, muitas vezes, são as únicas responsáveis. Produzir conhecimento significa, em meio a um cotidiano hostil, produzir espaço e tempo para pensar e ressignificar o mundo.

Diferentemente de uma Carolina Maria de Jesus, com seus cadernos catados no lixo, ou de uma Audre Lorde (2019), que, ao afirmar que "a poesia não é um luxo", define a palavra poética como o estabelecimento dos "alicerces para um futuro de mudanças”, Charlene escreve em voz alta o seu pensar crítico, sua "oralitura" que nos ajuda a desautomatizar o uso da palavra resistência. Aprendemos com ela que são "várias [as] resistências", e também que essa palavra tem dupla acepção: da mesma forma como determinado grupo social resiste às forças que 0 violentam, sempre haverá quem resista a todo e qualquer projeto de transformação da sociedade.

A teorização de Charlene nos lembra de que a identidade de uma comunidade não é algo dado, mas sempre estabelecido por meio de negociação e passível de conflito. Assim, "os lugares não são coerentes, são mesclados, são híbridos, são pontos de reunião, e a comunidade de um lugar será assunto de contenda, de negociação social entre distintos grupos” (MASSEY, 2013). Produzidas em paisagens de dominação, as geografias negras travam embates acerca das definições do que é propriedade e dos múltiplos significados da luta.

\section{Considerações finais}

As ocupações da Izidora mostram a convergência entre as lutas em torno da permanência das comunidades na dimensão físico-territorial e das lutas por nomeação. Protagonistas nas disputas de lugar, Izidora, Rosa e Charlene dialogam entre si em perspectiva trans-histórica e, assim, ajudam a ampliar o repertório sobre a produção do espaço numa cidade, Belo Horizonte, fundada, no século XIX, pela ideia de exclusão e de apagamento de todo e qualquer traço da presença negra em Minas Gerais e no Brasil. Meu objetivo foi recompor essa história porque se evidencia na prática das mulheres com as quais dialogo um gesto político e simbólico que insere o quilombo na centralidade da produção da cidade.

Procurei também argumentar sobre a importância do pensamento feminista negro para a figuração das disputas de lugar. O problema da exclusão, reiterado pela utilização de marcos teóricos que ignoram - programaticamente - o cruzamento entre as relações de poder, circula desde há muito tempo em contextos históricos 
e geopolíticos diversos (VIGOYA, 2016, p. 5). Ao se definir como ferramenta epistemológica, cuja principal função, no presente artigo, é dar a ver as múltiplas dinâmicas que se entrecruzam no espaço e no tempo, a interseccionalidade nos permite escapar da consideração de práticas espaciais unidimensionais, orientadas apenas pelo Estado-capital.

Há ainda muito a ser feito no campo dos estudos urbanos no tocante ao protagonismo das mulheres negras. Posto que a linha argumentativa e as análises desenvolvidas neste trabalho integram uma agenda de pesquisa ainda em curso, as considerações aqui tecidas não são conclusivas e representam um convite ao debate e, quem sabe, ao engajamento.

\section{Referências}

ALMEIDA, C.; FRANCO, F. T. S. R. Cotidiano e espetáculo: territórios e narrativas em disputa na Cracolândia. In: LINS, R. D.; ROLNIK, R. (Org.). Observatório de remoções 2017-2018: relatório bianual. São Paulo: FAUUSP, 2018.

BELO HORIZONTE. Lei Municipal $n^{\circ}$ 8.137. Altera as leis $n^{\circ} 7.165 / 96,7.166 / 96$, ambas de 27 de agosto de 1996 e Lei $n^{\circ}$ 7166/96, revoga a Lei ${ }^{0}$ 1.301/66 e dá outras providências. Diário Oficial Belo Horizonte: Belo Horizonte, 21 de dezembro de 2000.

CALDAS, D. O. M. A remoção dos moradores da Vila Autódromo: a gentrificação como característica do governo Eduardo Paes. Revista de Direito Sociais e Políticas Públicas, Brasília, DF, v. 3, n. 1, p.135, 2017.

CHAKRAVATTY, P.; FERREIRA DA SILVA, D. Accumulation, dispossession, and debt: the racial logic of global capitalism - an introduction. In: Race, empire and the crisis of the Subprime. Baltimore: Johns Hopkins University Press, 2013.

COLLINS, P. H. Black feminist thought: knowledge, consciousness, and the politics of empowerment. $2^{\text {nd }}$ ed. New York: Routledge, 2000.

. Aprendendo com a outsider within: a significação sociológica do pensamento feminista negro. Revista Sociedade e Estado, v. 31, n. 1, p. 99-127, jan.-abr. 2016.

COSTA, G. M.; MAGALHÃES, F. N. C. Processos socioespaciais nas metrópoles de países de industrialização periférica: reflexões sobre a produção do espaço metropolitano de Belo Horizonte, Brasil. Revista Brasileira de Estudos Urbanos e Regionais, v. 13, n. 1, p. 9-25, maio 2011.

CRUZ, M. de M.; SILVA, N. A. da. Intersections in subaltern urbanism: The narratives of women in urban occupations in Brazil. Politics and Space, p. 1-17, 2019.

FERREIRA DA SILVA, D. A dívida impagável. São Paulo: Forma Certa, 2019.

FRANZONI, J. O direito \& o direito: estórias da Izidora contadas por uma fabulação jurídico-espacial. 2018. Tese (Doutorado) - Programa de Pós-graduação em Direito, Universidade Federal de Minas Gerais, Belo Horizonte, 2018. 
FRANZONI, J.; ALVES, N.; FARIA, D. As bruxas da Izidora: feminismos e acumulação por despossessão. In: ROLNIK, R. et al. (Org.). Cidade Estado capital: reestruturação urbana e resistências em Belo Horizonte, Fortaleza e São Paulo. São Paulo: LabCidade-FAUUSP, 2018. p. 312-345.

. As bruxas da Izidora: feminismos e acumulação por despossessão. In: CANETTIERI, T. et al. (Org.). Não são só quatro paredes e um teto: uma década de luta nas ocupações urbanas na Região Metropolitana de Belo Horizonte. Belo Horizonte: Escola de Arquitetura da UFMG, 2020.

FRANZONI, J. A.; FARIA, D. de O.; RENA, N. A. Nós entre tramas: uma cartografia indisciplinar na Izidora. Indisciplinar, 2(3), p. 29-54, 2016.

FREITAS, D. M. Desvelando o campo de poder dos Grandes Projetos Urbanos da Região Metropolitana de Belo Horizonte. 2016. Tese (Doutorado) - Arquitetura e Urbanismo, Universidade Federal de Minas Gerais, Belo Horizonte, 2016.

GONZALEZ, L. O movimento negro na última década (1984). In: Primavera para as rosas negras. São Paulo: Edições UCPA, 2018.

HAESBAERT, R. O mito da desterritorialização: do “fim dos territórios” à multiterritorialidade. Rio de Janeiro: Bertrand Brasil, 2020.

HARKOT, M. K. Corpos e fronteiras: a construção de territórios a partir das subjetividades. São Paulo, FAUUSP, 2019. [Projeto de pesquisa apresentado à Fapesp.]

HARTMAN, S. Wayward lives, beautiful experiments. New York; London: W. W. Norton \& Company, 2019.

Vênus em dois atos. Revista ECO-Pós, v. 23, n. 3, p. 12-33, 2020. DOI: 10.29146/eco-pós.v23i3.27640. Disponível em: https://revistaecopos.eco.ufrj.br/eco_pos/article/ view/27640. Acesso em: 19 maio 2021.

HARVEY, D. The new imperialism: accumulation by dispossession. In: The ways of the world. London: Profile Books, 2016, p. 245-271.

HOURI, L. F. Políticas de produção de moradias e segregação residencial - Belo Horizonte 1986 a 2000. 2008. Dissertação (Mestrado) - Programa de Pós-graduação em Ciências Sociais, Pontifícia Universidade Católica de Minas Gerais, Belo Horizonte, 2008.

LACERDA, L. et al. Despossessão, violências e a potência transformadora: um olhar interseccional sobre as remoções. In: MOREIRA, F. A.; ROLNIK, R.; SANTORO, P. F. Cartografias da produção, transitoriedade e despossessão dos territórios populares. Observatório de remoções. Relatório bianual 2019-2020. São Paulo: LabCidade/FAUUSP, 2020. [livro eletrônico]:

LAO-MONTES, A. Metrópolis negras de Benin a Río de Janeiro y de Harlem a La Habana: modernidades afroamericanas y cosmopolitismos subalternos. La Habana: Casa de las Americas, 2019.

LORDE, A. Irmã outsider. Ensaios e conferências. Tradução: Stephanie Borges. São Paulo; Belo Horizonte: Autêntica, 2019. p. 45. 
MAGALHÃES, J. P. Moçambique e Vale do Paraíba na dinâmica do comércio de escravos: diásporas e identidades étnicas, séc. XIX. 2010. Dissertação (Mestrado em História), Universidade de São Paulo, São Paulo, 2010.

MARINHO, A., ROLNIK, R., LINS, R. D. Experiências de mapeamento das remoções e ameaças de remoção na Região Metropolitana de São Paulo. In: LINS, R. D.; ROLNIK, R. (Org.). Observatório de remoções 2017-2018: relatório bianual. São Paulo: FAUUSP, 2018.

MARTINS, L. M. Afrografias da memória. São Paulo: Perspectiva, 1997.

MASSEY, D. V Seminario Atlántico de Pensamiento. Experimentos con la espacialidad del poder y democracia Bloque: Lo Social - Autora: Doreen Massey. Youtube, dezembro de 2013. Disponível em: https://youtu.be/uBWWm-NINow. Acesso em: 27/10/2021.

McKITTRICK, K. Demonic grounds: Black women and the cartographies of struggle. Minneapolis: University of Minnesota Press, 2006.

MONTEIRO, P.; MEDEIROS, M.; NASCIUTTI, L. F. Insurgência feminina: a ética do cuidado e a luta contra a remoção. ENCONTRO NACIONAL DA ASSOCIAÇÃO NACIONAL DE PÓSGRADUAÇÃO E PESQUISA EM PLANEJAMENTO URBANO E REGIONAL, 17., 2017, São Paulo. Anais [...]. São Paulo: Enanpur, 2017. Tema: Desenvolvimento, crise e resistência: quais os caminhos do Planejamento Urbano e Regional?.

NUQ UFMG. Relatório antropológico de caracterização histórica, econômica e sociocultural: o Quilombo de Mangueiras, Belo Horizonte - Minas Gerais. Prof. Dr. Daniel Schroeter Simião (Coord.). Núcleo de Estudos de Populações Quilombolas e Tradicionais. Belo Horizonte: Universidade Federal de Minas Gerais; Fafich, 2008.

OLIVEIRA, F. L.; TANAKA, G.; COLI, L. R. Planejamento conflitual. Rio de Janeiro: Ettern/Ippur, 2019.

ROSA, A. O Zilah é logo ali, o Zilah é bem aqui. Belo Horizonte: EMPDA, 2010.

SÁNCHEZ, F. et al. Contra histórias possíveis: as ações populares e as práticas do artivismo artístico no Morro da Providência. StreetNotes, v. 25, p. 33-42, 2016.

SANTOS, R. E. Agendas \& agências: a espacialidade dos movimentos sociais a partir do pré-vestibular para negros e carentes. 2006. Tese (Doutorado) - Programa de Pós-graduação em Geografia, Universidade Federal Fluminense, Niterói, 2006.

. Expressões espaciais das relações raciais: algumas notas. In: BARONE, A.; RIOS, F. (Org.). Negros nas cidades brasileiras (1890-1950). São Paulo: Intermeios: Fapesp, 2018.

. Repertórios espaciais de ação na luta antirracismo. In: SÁNCHEZ, F.; MOREIRA, P. C. (Org.). Cartografias do conflito. Rio de Janeiro: Letra Capital, 2019.

SILVA, N. A. da. Feminismo negro e produção do espaço: as ocupações urbanas em uma abordagem interseccional-espacial. 2018. Dissertação (Mestrado) - Programa de Pósgraduação em Arquitetura e Urbanismo, Universidade Federal de Minas Gerais, Belo Horizonte, 2018.

SMITH, S. J. Geografia urbana num mundo em mutação. In: GREGORY, D.; MARTIN, R.; SMITH, G. Geografia humana: sociedade, espaço e ciência social. Rio de Janeiro: Jorge Zahar, 1996. 
SOBRINHO, T. de C. O papel das mulheres na luta pela apropriação da cidade: reflexões a partir da teoria da interseccionalidade. Caderno Didático Políticas Públicas e Direito à Cidade. Rio de Janeiro: Ippur/UFRJ: Letra Capital, 2007.

SORAGGI, A. C. M.; ARAGÃO, T. A. O direito à cidade e as ocupações urbanas: um olhar sobre a Vila Eliana Silva/Belo Horizonte. In: MARX, V.; COSTA, M. A. (org.). Participação, conflitos e intervenções urbanas: contribuições à Habitat III. Porto Alegre: Ed. da UFGRS, 2016. v. 1. p. 232-254.

URBEL. Companhia Urbanizadora e de Habitação de Belo Horizonte. Conjunto Habitacional Zilah Spósito - Etapa IV. Belo Horizonte, 2000.

VIEIRA, D. M. Territórios negros em Porto Alegre/RS (180o-1970): geografia histórica da presença negra no espaço urbano. 2017. Dissertação (Mestrado) Programa de Pós-graduação em Geografia, Instituto de Geociências, Universidade Federal do Rio Grande do Sul, Porto Alegre, 2017.

VIGOYA, M. V. La interseccionalidad: una aproximación situada a la dominación. Debate feminista, v. 52, p. 1-17, 2016.

VIVEROS, M. La interseccionalidad: una aproximación situada a la dominación. Revista Debate Feminista, Universidad Autómona de Mexico, 52, 2016. 


\section{Natália Alves da Silva}

Doutoranda no Programa de Pós-graduação em Planejamento Urbano e Regional no Instituto de Pesquisa e Planejamento Urbano e Regional (Ippur) da Universidade Federal do Rio de Janeiro (UFRJ).

Email: natalialvesrj@gmail.com

ORCID: 0000-0001-9524-4996

Submissão: 20 de dezembro de 2020.

Aprovação: 8 de agosto de 2021 .

Como citar: SILVA, N. A. da. Uma Izidora e duas Rosas: notas para uma perspectiva do espaço protagonizada por mulheres negras. Revista brasileira de estudos urbanos e regionais. Dossiê Território, Gênero e Interseccionalidades. v. 23, E202138pt, 2021. DOI 10.22296/2317-1529.rbeur.202138pt

Artigo licenciado sob Licença Creative Commons CC BY 4.0.

https://creativecommons.org/licenses/by/4.o/deed.pt_BR 